\title{
Sources for developing new medicinal products: biochemical investigations on alcoholic extracts obtained from aerial parts of some Romanian Amaryllidaceae species
}

Daniela Benedec ${ }^{1}$, llioara Oniga ${ }^{1 *}$ (D), Daniela Hanganu', Ana Maria Gheldiu², Cristina Pușcaș ${ }^{3}$, Radu Silaghi-Dumitrescu ${ }^{3}$, Mihaela Duma ${ }^{4}$, Brîndușa Tiperciuc ${ }^{5}$, Rodica Vârban ${ }^{6}$ and Laurian Vlase ${ }^{2}$

\begin{abstract}
Background: Although Galanthus nivalis L. (snowdrop) is known for the galanthamine content, used in the treatment of Alzheimer disease, the polyphenolic compounds of Amaryllidaceae species are less studied. Proper understanding of the polyphenolics in these extracts and of their antioxidant and antimicrobial properties may allow a reconsideration of their medicinal uses.

Methods: The polyphenolic content of four selected Amaryllidaceae species harvested from Romania (Galanthus nivalis L., Narcissus pseudonarcissus L., N. poeticus L. and Leucojum vernum L.) was determined by spectrophotometric methods; the identification of phenolic compounds was performed by a HPLC-MS method, in order to establish their polyphenolic fingerprints. For the evaluation of the antioxidant potential the following methods were employed: DPPH radical scavenging, FRAP, hemoglobin ascorbate peroxidase activity inhibition (HAPX), inhibition of lipid peroxidation catalyzed by cytochrome $c$, and electron paramagnetic resonance (EPR) spectroscopy assays. Antimicrobial activity was assessed using the disc diffusion method.

Results: Qualitative and quantitative analyses highlight important amount of polyphenols (over $15 \mathrm{mg} / \mathrm{g}$ ); the main identified compounds are chlorogenic and p-coumaric acids in all species. Only G. nivalis shows antioxidant activity by all the used methods. G. nivalis and L. vernum strongly inhibits the growth of S. aureus, while N. poeticus shows a very good antifungal activity.
\end{abstract}

Conclusions: The results of this study provide a new approach to the properties and therapeutic uses of some Romanian widespread Amaryllidaceae species that could be considered sources of developing new medicinal products with anti anti-staphylococcal and antifungal activity.

Keywords: Galanthus, Leucojum, Narcissus, Antioxidant and antimicrobial activities, Polyphenols, cytochrome c

\footnotetext{
* Correspondence: ioniga@umfcluj.ro

'Department of Pharmacognosy, "Iuliu Hațieganu" University of Medicine

and Pharmacy, 12 I. Creangă Street, 400010 Cluj-Napoca, Romania

Full list of author information is available at the end of the article
}

(c) The Author(s). 2018 Open Access This article is distributed under the terms of the Creative Commons Attribution 4.0 International License (http://creativecommons.org/licenses/by/4.0/), which permits unrestricted use, distribution, and reproduction in any medium, provided you give appropriate credit to the original author(s) and the source, provide a link to the Creative Commons license, and indicate if changes were made. The Creative Commons Public Domain Dedication waiver (http://creativecommons.org/publicdomain/zero/1.0/) applies to the data made available in this article, unless otherwise stated. 


\section{Background}

The Amaryllidaceae family includes more than 1000 perennial bulbous species, distributed throughout the tropical and subtropical regions of the world. In the Romanian flora, about 17 species from five genera of this family can be found, spontaneous or cultivated. The most common Amaryllidaceae species are Narcissus sp. (daffodils), Amaryllis sp. and Galanthus sp. (snowdrops), mostly known as ornamental plants [1-3]. The Amaryllidaceae have been used for thousands of years as herbal remedies; thus, in the fourth century B.C. Hippocrates was using oil extracted from daffodil ( $N$. poeticus) for the treatment of uterine tumors. Other species used in traditional medicine are G. woronowii and G. nivalis, indicated for the treatment of nervous system disorders, fainting, headache, heart and mitral insufficiency, myocarditis [3-5]. Over the past three decades, many specific alkaloids have been isolated (galanthamine, lycorine, crinine, haemanthamine, tazettine, narciclasine etc.) and reported to have acetylcholinesterase inhibitory effect (for the treatment of Alzheimer's disease), antiviral, antibacterial, antifungal, antimalarial, antitumor and cytotoxic activities [3,6-10]. In the aerial parts of some Amaryllidaceae flavonoids (hyperoside, quercetin, isorhamnetin- $O$-sophoroside, quercetin-3-O-sophoroside) and hydroxycinnamic acids (cinnamic, $p$-coumaric, $p$-hydroxybenzoic, caffeic acids) were identified [4, 5, 11-14]. The potential utility of these species is not just restricted to alkaloids, because the Amaryllidaceae synthesize a diverse array of polyphenols with well-known pharmacological properties (antioxidant, antimicrobial, anticancer, anti-aging etc.). Recent studies have shown the efficacy of natural polyphenols in Alzheimer's disease through various mechanisms (antioxidant, acetylcholinesterase and butyrylcholinesterase inhibition). Also, chlorogenic acid is reported to have neuroprotective properties [15-18]. In this context, the aim of the present research was to determine the polyphenolic composition of some Romanian Amaryllidaceae species (G. nivalis, N. pseudonarcissus, N. poeticus and L. vernum) and to highlight some of their biological activities in order to reconsider the uses of these medicinal plants.

\section{Methods}

\section{Plant materials}

The aerial parts of 4 Amaryllidaceae species were harvested from different regions of Cluj County, Romania, in March 2017, during the flowering period. The plant materials were identified by PhD Rodica Varban (University of Agricultural Sciences and Veterinary Medicine, Cluj-Napoca) and PhD Ilioara Oniga ("Iuliu Hațieganu" University of Medicine and Pharmacy Cluj-Napoca). Voucher specimens of the 4 species are deposited at the Department of Pharmacognosy ("Iuliu Hațieganu" University of Medicine and Pharmacy Cluj-Napoca): Galanthus nivalis L. (Voucher No. 50), Narcissus poeticus L. (Voucher No. 81), N. pseudonarcissus
L. (Voucher No. 92), and Leucojum vernum L. (Voucher No. 73).

\section{Chemicals and microorganisms}

HPLC grade methanol and analytical grade orthophosphoric acid were purchased from Merck (Darmstadt, Germany). All chemicals and reagents were of analytical grade. Phenolic standards: chlorogenic, caffeic acid, $p$-coumaric acids, rutin, isoquercitrin, quercitrin, hyperoside, myricetol, fisetin, quercetin, apigenin, kaempferol were acquired from Sigma (St. Louis, MO, USA), ferulic, sinapic, gentisic, gallic acids, patuletin, luteolin were purchased from Roth (Karlsruhe, Germany), cichoric, caftaric acid were from Dalton (Toronto, ON, Canada). Other reagents or chemicals, including hydrochloric acid, aluminum chloride, sodium acetate, ethanol and Folin-Ciocalteu reagent were acquired from Sigma (St. Louis, MO, USA), sodium carbonate, hydrogen peroxide, sodium ascorbate and bovine hemoglobin were purchased from Sigma-Aldrich (Steinheim, Germany), DPPH (2,2-diphenyl-1-picrylhydrazyl), 2,4,6-tri(2-pyridyl)-1,3,5-triazine (TPTZ), 6-hydroxy-2,5,7,8tetramethyl-chroman-2-carboxylic acid (Trolox) were obtained from Alfa-Aesar (Karlsruhe, Germany). All microorganism products were distributed by MicroBioLogics : Staphylococcus aureus ATCC 6538P (Gram-positive bacteria), Listeria monocytogenes ATCC 13932 (Gram-positive bacteria), Escherichia coli ATCC 25922 (Gram-negative bacteria), Salmonella typhimurium ATCC 13076 (Gram-negative bacteria) and fungal strains Candida albicans ATCC 10231 and Aspergillus brasiliensis ATCC 16404. All spectrophotometric data were acquired using a Jasco V-530 UV-vis spectrophotometer (Jasco International Co., Ltd., Tokyo, Japan).

\section{Preparation of sample solutions}

The powdered vegetal product $(10 \mathrm{~g})$ was extracted with $20 \mathrm{~mL}$ of $70 \%$ ethanol, in an ultrasonic bath (Polsonic Palczyski Sp. J., Poland, Sonic 3), at $60{ }^{\circ} \mathrm{C}$ and sonicated for $30 \mathrm{~min}$. The extracts were filtered through paper filters in $20 \mathrm{~mL}$ flasks and then centrifuged at $4500 \mathrm{rpm}$ for 20 min.; the supernatants were recovered [15-19].

\section{HPLC chromatographic conditions and instrumentation}

Analysis was performed using an Agilent 1100 HPLC Series system (Agilent, Santa Clara, CA, USA) equipped with: G1322A degasser, G13311A binary gradient pump, column thermostat, G1313A autosampler, and G1316A UV detector coupled to an Agilent 1100 mass spectrometer. HPLC-MS analysis of the studied extracts was performed according to a previously validated and described method [15-19]. Separation of the compounds was carried out on a reverse-phase analytical column (Zorbax SB-C18 $100 \times 3.0 \mathrm{~mm}$ i.d., $3.5 \mu \mathrm{m}$ particle); the column temperature was $48^{\circ} \mathrm{C}$. The detection was performed simultaneously 
using both the UV and the MS mode. The UV detector was set at $330 \mathrm{~nm}$ until $17.5 \mathrm{~min}$, then at $370 \mathrm{~nm}$. The MS system entailed an electrospray ion source in negative mode. The UV mode was employed for quantification after qualitatively positive identification by MS. The chromatographic data were processed using ChemStation and DataAnalysis software from Agilent. The mobile phase with methanol and acetic acid $0.1 \%(v / \mathrm{v})$ was used in a binary gradient. For $35 \mathrm{~min}$, elution was performed with a linear gradient, starting at 5\% methanol and finishing at $42 \%$ methanol. The flow rate of the mobile phase was $1 \mathrm{~mL} / \mathrm{min}$. Five microliters were used for injection. The standard MS spectra were integrated in a mass spectra library. Under these chromatographic conditions two couples of compounds (namely: caftaric vs. gentisic acid and caffeic vs. chlorogenic acid) could not be quantitatively determined due to peak overlappingș instead, these 4 carboxylic acids were determined only based on MS spectra, whereas for the rest of the compounds the linearity of the calibration curves was very good $\left(R^{2}>0.998\right)$, with detection limits in the range of 18 to $92 \mathrm{ng} / \mathrm{mL}$. The detection limits were calculated as the minimal concentration yielding a reproducible peak with a signal-to-noise ratio greater than three. Analyses were performed using an external standard method; retention times were determined with a standard deviation ranging from $0.04 \mathrm{~min}$ to $0.19 \mathrm{~min}$. The accuracy was between 94.13 and $105.3 \%$, for all substances. In samples, the compounds were identified by comparison of their retention times and recorded electrospray mass spectra with those of standards recorded under the same conditions.

\section{Determination of the total polyphenolic and flavonoidic contents}

The total polyphenolic content was determined according to the European Pharmacopoeia, using the Folin-Ciocalteu method, with a calibration curve of gallic acid $\left(R^{2}=0.999\right)$ and the results expressed as mg of gallic acid equivalent (GAE) per g dry weight (d.w.) [15-23]. A spectrophotometric method, based on flavonoid-aluminum chloride $\left(\mathrm{AlCl}_{3}\right)$ complexation was employed for determination of the total flavonoidic content $[15-19,24]$. In brief, $5 \mathrm{~mL}$ extract was mixed with $5.0 \mathrm{~mL}$ of sodium acetate $100 \mathrm{~g} / \mathrm{L}, 3.0 \mathrm{~mL}$ of aluminum chloride $25 \mathrm{~g} / \mathrm{L}$, and filled up to $25 \mathrm{~mL}$ by methanol in a calibrated flask. The mixture was allowed to stand for $15 \mathrm{~min}$. and absorbance was measured at $430 \mathrm{~nm}$. The total flavonoidic content was calculated from a calibration curve $\left(R^{2}=0.999\right)$ and the result was expressed as mg rutin equivalent (RE) per g dry weight [15-19, 24].

\section{Determination of antioxidant properties DPPH (2,2-diphenyl-1-picrylhydrazyl) assay}

The antioxidant activity was determined by the 2,2-diphenyl-1-picrylhydrazyl (DPPH) assay, as described earlier, with some modifications. Briefly, $2.0 \mathrm{~mL}$ of methanolic $\mathrm{DPPH}$ solution $(0.25 \mathrm{mM})$ were added to $2.0 \mathrm{~mL}$ of extract solution (or standard) in ethanol at different concentrations $(18.75-150 \mu \mathrm{g} / \mathrm{mL})$. After $30 \mathrm{~min}$ of incubation at $40{ }^{\circ} \mathrm{C}$ in a thermostated bath, the decrease in the absorbance was measured at $517 \mathrm{~nm}$. The percent DPPH scavenging ability was calculated as: $\mathrm{DPPH}$ scavenging ability $=\left(\mathrm{A}_{\text {control }}-\mathrm{A}_{\text {extract }}\right) / \mathrm{A}_{\text {control }} \times$ 100 , where $A_{\text {control }}$ is the absorbance of the DPPH radical and methanol (containing all reagents except the sample) and $\mathrm{A}_{\text {extract }}$ is the absorbance of the mixture of $\mathrm{DPPH}$ radical and sample extract. Trolox was used as a positive control [15-22, 25].

\section{Ferric reducing antioxidant power (FRAP) assay}

The FRAP (ferric reducing antioxidant power) method relies on the change in the color of a ferric complex of the 2,4,6-tri(2-pyridyl)-1,3,5-triazine (TPTZ) radical due to reduction of the metal to the ferrous form $\left(\mathrm{Fe}^{+2}\right)$. Trolox was used for the calibration curve(correlation coefficient - 0.992) andthe results were converted to $\mu \mathrm{M}$ Trolox equivalents/100 mL extract [26, 27].

\section{HAPX assay}

The hemoglobin ascorbate peroxidase activity assay (HAPX) was previously described in detail [21, 28-31]. $5 \mu \mathrm{L}$ extracts were added to ascorbate $(120 \mu \mathrm{M})$ and peroxide $(700 \mu \mathrm{M})$, in acetate buffer, $\mathrm{pH} 5.5$. The reaction was triggered by met hemoglobin $(6 \mu \mathrm{M})$ and it was monitored at $405 \mathrm{~nm}$, where the changes are due to hemoglobin transformation. The antioxidant capacity is correlated with an increase in the inhibition time and is given in percent of inhibition [28-31].

\section{Inhibition of lipid peroxidation catalyzed by cytochrome c}

The inhibition of lipid peroxidation catalyzed by cytochrome $c$ was performed as previously described [31]. Thus, liposomes were obtained from $5 \mathrm{mg} / \mathrm{mL}$ soybean lecithin suspended in phosphate buffer $(20 \mathrm{mM}, \mathrm{pH} 7)$ and sonicated for $20 \mathrm{~min}$ in an ultrasonic bath (using a Power Sonic 410 device). The experiment monitored the formation of lipid conjugated dienes at $235 \mathrm{~nm}$, at room temperature, in the presence of cytochrome $c(2 \mu \mathrm{M})$ and extract (diluted 2 thousand times).

\section{Direct detection of free radicals}

For direct detection of free radicals [18, 29, 30], the extracts were diluted 25 times in ethanol 90\% and treated with $5 \mathrm{mM} \mathrm{NaOH}$ (yielding a basic $\mathrm{pH}$ ). The concentration of pure compounds was $2 \mathrm{mM}$ in $90 \%$ ethanol. The measurements were performed very fast in a capillary tube placed in a holder of a Bruker ELEXYS E-580 spectrometer with continuous wave at $\mathrm{X}$ band $(\sim 9.4 \mathrm{GHz}$, 
modulation amplitude, $1 \mathrm{G}$, microwave power, $9.6 \mathrm{mM}$, center field 3514 and sweep field $100 \mathrm{G}$.

\section{Determination of antimicrobial activity}

The agar disk-diffusion assay is an official method used in many microbiology laboratories for antimicrobial susceptibility using specific culture media, various incubation conditions and interpretive criteria for inhibition zone $[18,32]$. In this well-known procedure, agar plates are inoculated with a standardized inoculum of the test microorganisms: S. typhimurium, E. coli, L. monocytogenes, S. aureus, C. albicans, and A. brasiliensis. After the hydration of the lyophilized strain, the sterile tampon was impregnated with hydrated material and transferred onto the selective medium specific for each strain (e.g Salmonella: Rambach agar, XLD agar; E. coli: TBX agar). The tampon was rotated with pressure and a circular area was inoculated on the agar media. Using a sterile loop, streaks were made repeatedly in the inoculated area and then streaked also on the rest of the plate's surface. Immediately afterwards, the culture medium inoculated was incubated at corresponding temperatures (e.g. Salmonella $37{ }^{\circ} \mathrm{C}$; E. coli $44{ }^{\circ} \mathrm{C}$ ). From the pure ATCC reference culture, of $24 \mathrm{~h}$, a $0.5 \mathrm{McFarland}$ suspension was obtained (corresponding to $10^{\wedge} 8 \mathrm{CFU} / \mathrm{mL}$ ). The Muller-Hinton agar plates were inoculated by inundation. The plates were then dried in the thermostat for $20 \mathrm{~min}$ (this interval is not exceeded because the bacteria might reach a multiplication phase). The sterile disks were soaked with the tested solutions ( $50 \mu \mathrm{L}$ of each extract). The plates were incubated overnight at $37{ }^{\circ} \mathrm{C}$. The antimicrobial agent diffuses into the agar and inhibits germination and growth of the test microorganism. The diameters of inhibition growth zones were measured. Gentamicin, fluconazole and amphotericin B were used as standard antibacterial and antifungal drugs. The negative control was $70 \%$ ethanol (diameter $=6 \mathrm{~mm}$ ). The clear halos greater than $10 \mathrm{~mm}$ were considered as positive results. Tests were performed in triplicate and values are the averages of three replicates.

The minimum inhibitory concentrations (MICs) of the extracts were determined by an agar dilution method including the same strains of microorganisms as used in the agar disk diffusion method [33]. For this experiment, $100 \mu \mathrm{L}$ nutrient broths were placed in a 96 well plate and $100 \mu \mathrm{L}$ of each plant extract were added in the first ten lines. Then $100 \mu \mathrm{L}$ were aspirated from every well and placed in the second well line of the plate. This technique was used in order to obtain the desired dilutions until line 10; from the last well, $100 \mu \mathrm{L}$ mixes were discharged as follows: $50.0 \mu \mathrm{L}, 25.0,12.5,6.25,3.12,1.56$, $0.78,0.39,0.19$, and $0.09 \mu \mathrm{L}$ of plant extracts in $100 \mu \mathrm{L}$ medium. Each well was seeded with $5.0 \mu \mathrm{L}$ of a $24 \mathrm{~h}$ culture bacterial suspension, adjusted to be similar to 0.5
McFarland scale $10^{\wedge} 8 \mathrm{CFU} / \mathrm{mL}$ ), and incubated for 16 $24 \mathrm{~h}$ ( $48 \mathrm{~h}$ for fungi) at $35^{\circ} \pm 2{ }^{\circ} \mathrm{C}$. MIC was detected by the lowest concentration of the analyzed product in which the development of the bacterium strain was inhibited (medium remained clear). Negative control (70\% ethanol) concentration for the determination of MIC using serial dilution method, was similar with the concentration used in the 1st well of the plate [33].

\section{Statistical analysis}

The samples were analyzed in triplicate or more; the average and the relative SD were calculated using the Excel software package. The experimental data was evaluated using one-way analysis of variance (ANOVA), with $p<0.05$ as threshold value for statistical significance. The statistical results confirm the hypothesis that the differences between the results are either not significant $(p>0.05)$, significant $(0.001<p<0.05)$ or highly significant $(p<0.001)$.

\section{Results \\ Qualitative and quantitative polyphenolic profile}

Analysis of the phenolic profile of the four Amaryllidaceae extracts was performed by a previously tested HPLC-MS method [15-19]. The identification of the compounds was based on their retention times, UV and MS spectra as compared to the standards. Thus, polyphenolic acids (e.g. gentisic, chlorogenic, $p$-coumaric, ferulic acids) and flavonoids (hyperoside, isoquercitrin, rutin, quercitrin, quercetin, kaempferol) were identified in the studied extracts using HPLC-MS analysis (Table 1, Figs. 1, 2, 3, and 4). Quantification of compounds was performed using an external standard method with 20 standard phenolic compounds ( 9 phenolic acids and 11 flavonoids).

\section{Total polyphenolic and flavonoidic contents}

The total content of polyphenols (TPC) and flavonoids (TFC) as well as the antioxidant activity of the four extracts revealed significant differences between the studied samples. The total polyphenolic content decreased in the following order: G. nivalis $(24.57 \mathrm{mg} / \mathrm{g})>N$. pseudonarcissus $(19.74 \mathrm{mg} / \mathrm{g})>L$. vernum $(16.49 \mathrm{mg} / \mathrm{g})>N$. poeticus $(15.25 \mathrm{mg} / \mathrm{g})(p<0.001)$, cf. Table 2 , Fig. 5 . The total flavonoidic content (Table 2, Fig. 6), using rutin as standard, decreased as follows: G. nivalis $(12.56 \mathrm{mg} / \mathrm{g})>L$. vernum $(7.10 \mathrm{mg} / \mathrm{g})>N$. pseudonarcissus $(4.92 \mathrm{mg} / \mathrm{g})>N$. poeticus $(2.47 \mathrm{mg} / \mathrm{g})$.

\section{Antioxidant activities evaluation}

The antioxidant potential was evaluated by several in vitro models, such as: DPPH., FRAP bleaching system, hemoglobin ascorbate peroxidase activity inhibition (HAPX), inhibition of lipid peroxidation catalyzed by 
Table 1 The polyphenolic compounds analyzed by HPLC-MS ( $\mu \mathrm{g} / \mathrm{g}$ plant material)

\begin{tabular}{|c|c|c|c|c|c|c|}
\hline Compounds & {$[\mathrm{M}-\mathrm{H}]-\mathrm{m} / \mathrm{z}$} & Retention time (Rt), min & N. pseudonarcissus & N. poeticus & G. nivalis & L. vernum \\
\hline neochlorogenic acid (y) & 353 & $3.30 \pm 0.00$ & NF & $<0.02$ & $\mathrm{NF}$ & NF \\
\hline gentisic acid & 179 & $3.69 \pm 0.04$ & $<0.02$ & $<0.02$ & $<0.02$ & $<0.02$ \\
\hline chlorogenic acid & 353 & $6.43 \pm 0.05$ & $1425.56 \pm 10.63$ & $755.93 \pm 4.06$ & $2976.19 \pm 12.80$ & $1925.69 \pm 6.31$ \\
\hline cryptochlorogenic acid (z) & 353 & $7.10 \pm 0.00$ & NF & $<0.02$ & $\mathrm{NF}$ & NF \\
\hline p-coumaric acid & 163 & $9.48 \pm 0.08$ & $46.54 \pm 0.45$ & $32.70 \pm 0.29$ & $73.02 \pm 0.07$ & $270.51 \pm$ \\
\hline ferulic acid & 193 & $12.8 \pm 0.10$ & $78.88 \pm 1.11$ & $25.29 \pm 0.70$ & $26.80 \pm 0.19$ & $<0.02$ \\
\hline $\begin{array}{l}\text { quercetin-O-sophoroside or quercetin- } \\
\text { 3-O-galactosyl- }(1 \rightarrow 6) \text {-galactoside }\end{array}$ & 625 & $15.4 \pm 0.00$ & $<0.02$ & $<0.02$ & $<0.02$ & $<0.02$ \\
\hline hyperoside & 463 & $18.60 \pm 0.12$ & $146.05 \pm 1.94$ & $\mathrm{NF}$ & $\mathrm{NF}$ & $<0.02$ \\
\hline isoquercitrin & 463 & $20.29 \pm 0.10$ & $<0.02$ & $6.59 \pm 0.10$ & $25.08 \pm 0.31$ & $8.76 \pm 0.19$ \\
\hline rutin & 609 & $20.76 \pm 0.15$ & $<0.02$ & $\mathrm{NF}$ & $\mathrm{NF}$ & NF \\
\hline quercitrin & 447 & $23.64 \pm 0.13$ & $31.69 \pm 0.10$ & $9.26 \pm 0.23$ & $11.13 \pm 0.06$ & $<0.02$ \\
\hline quercetin & 301 & $27.55 \pm 0.15$ & $<0.02$ & NF & $<0.02$ & NF \\
\hline kaempferol & 285 & $32.48 \pm 0.17$ & $4.82 \pm 0.07$ & NF & $\mathrm{NF}$ & NF \\
\hline
\end{tabular}

Values are the mean \pm SD $(n=3)$. NF - not found, below limit of detection

cytochrome $c$, and electron paramagnetic resonance (EPR) spectroscopy. The antioxidant activities quantitatively determined by the DPPH radical bleaching and FRAP methods, expressed as Trolox equivalents (Table 2), showed the same decreasing order of the activity: $G$. nivalis $>N$. poeticus $>L$. vernum $>N$. pseudonarcissus. For HAPX, and effect on the capacity to inhibit ferryl formation (methodology previously described [28-31]) was measurable only for G. nivalis and $N$. pseudonarcissus (given as percent of inhibition in Table 2). In terms of inhibiting the cytochrome $c$ - induced lipid peroxidation, all extracts showed antioxidant capacity (Fig. 7). The EPR spectra detected $2 \mathrm{~min}$ after alkali treatment are shown in Fig. 8 and also reflect, qualitatively, the main polyphenolic components in the samples (to the extent to which they are prone to autooxidation under alkaline conditions).

\section{Determination of antimicrobial activity}

Diameters of growth inhibition zones of ethanolic extracts from the four Amaryllidaceae species were compared with those of standards such as gentamicin for antibacterial activity and fluconazole and amphotericin B for antifungal activity. The samples showed various degrees of the inhibition against 4 bacterial strains and two fungus strains using the agar disk diffusion method (Table 3). In terms of MIC, the same bacterial and fungal strains were used. The results in Table 4 showed that the MIC values varied from 19.53 to $625 \mathrm{mg} / \mathrm{mL}$, for the 4 extracts (Table 4 ).

\section{Discussions}

Polyphenolic compounds were identified in the studied extracts, using HPLC-MS analysis (Table 1, Figs. 1, 2, 3, and 4); some of them were reported here for the first

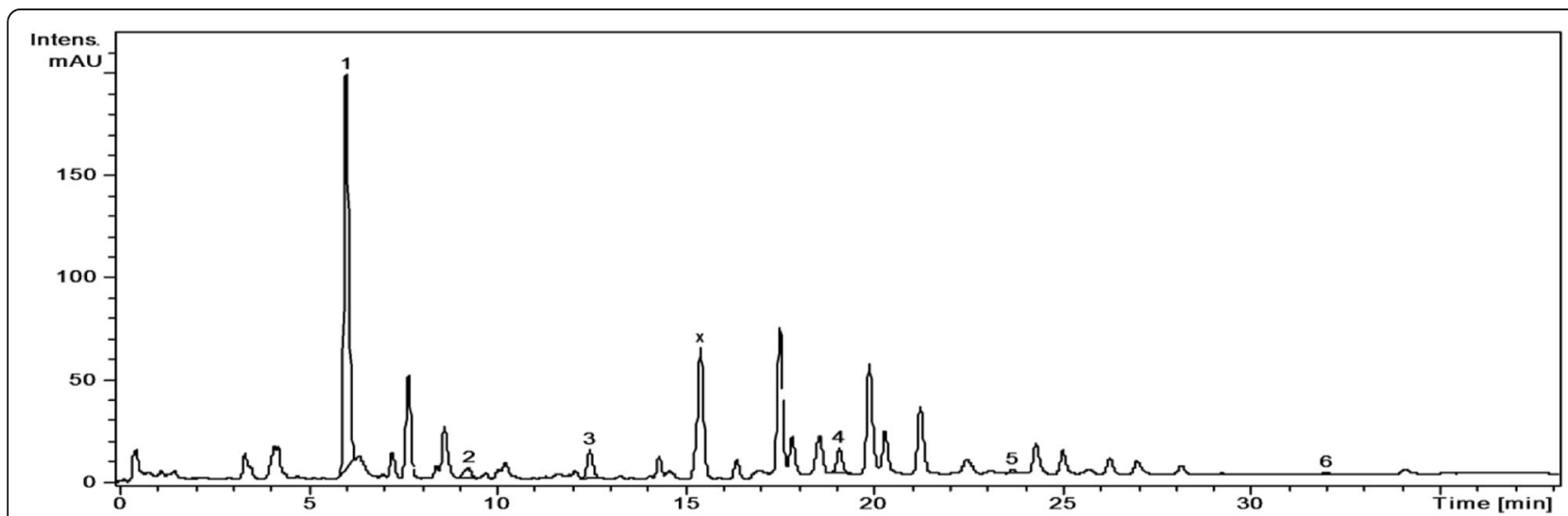

Fig. 1 HPLC chromatograms of N. pseudonarcissus extract. Notes: The identified compounds: 1-chlorogenic acid; 2-p-coumaric acid; 3-ferulic acid; 4-hyperoside; 5-quercitrin; 6-kaempferol 


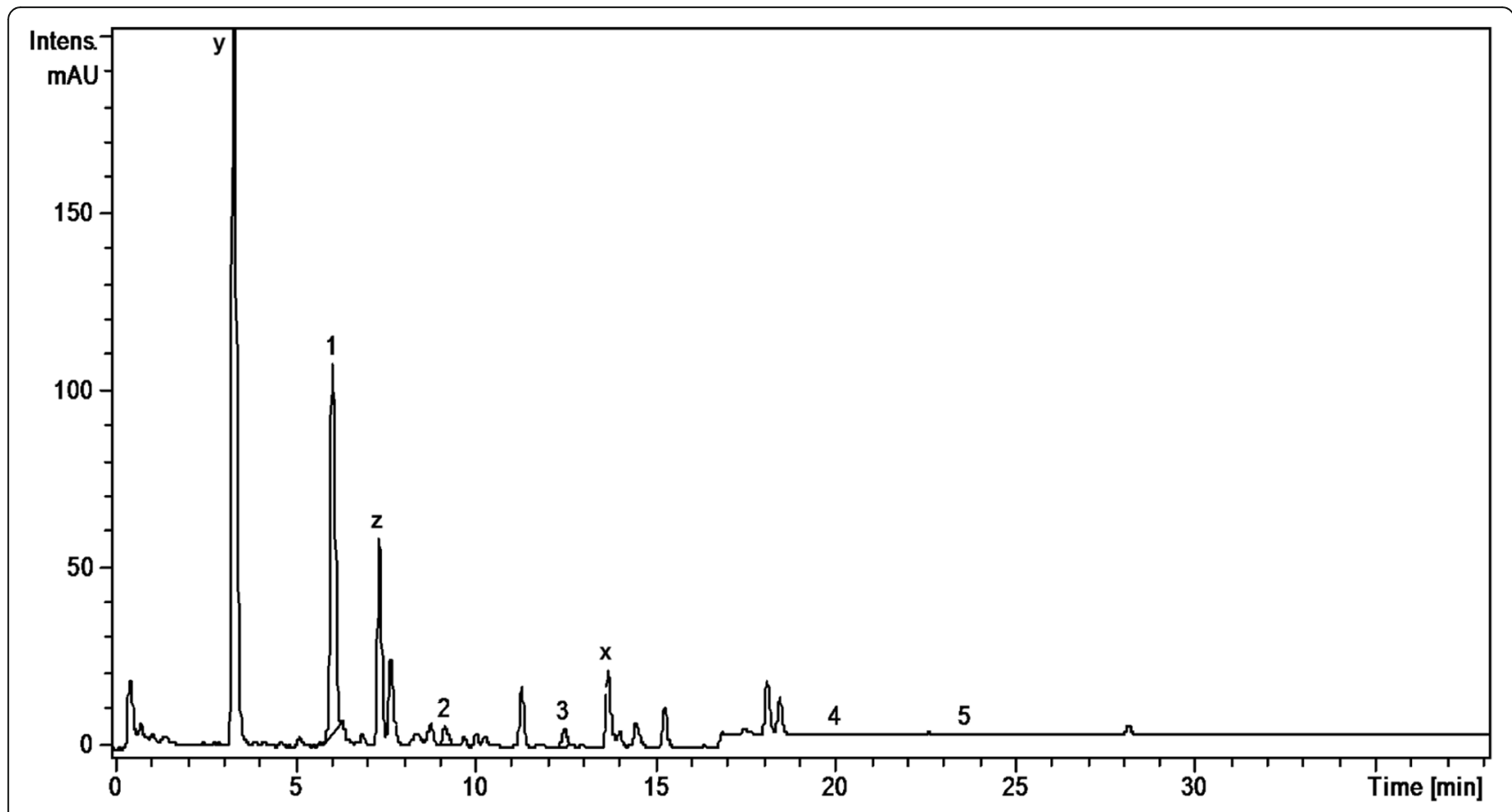

Fig. 2 HPLC chromatograms of N. poeticus extract. Notes: 1-chlorogenic acid; 2- p-coumaric acid; 3-ferulic acid; 4-isoquercitrin; 5-quercitrin

time (gentisic acids, $p$-coumaric acids, hyperoside, quercetrin). Chlorogenic acid dominated the phenolic acid profiles of all samples, its concentration decreasing in the following order: G. nivalis $>L$. vernum $>N$. pseudonarcissus $>N$. poeticus. Ferulic and $p$-coumaric acids were found in all studied samples. The $L$. vernum extract was the richest in $p$-coumaric acid $(270.51 \mu \mathrm{g} / \mathrm{g})$, while the largest amount of ferulic acid was determined in $N$. pseudonarcissus $(78.88 \mu \mathrm{g} / \mathrm{g})$. Gentisic acid was detected only in traces. Bulgarian authors reported the presence of chlorogenic and ferulic acid in aerial parts of G. nivalis and L. aestivum [14]. In G. elwesii extracts, $p$-hydroxybenzoic

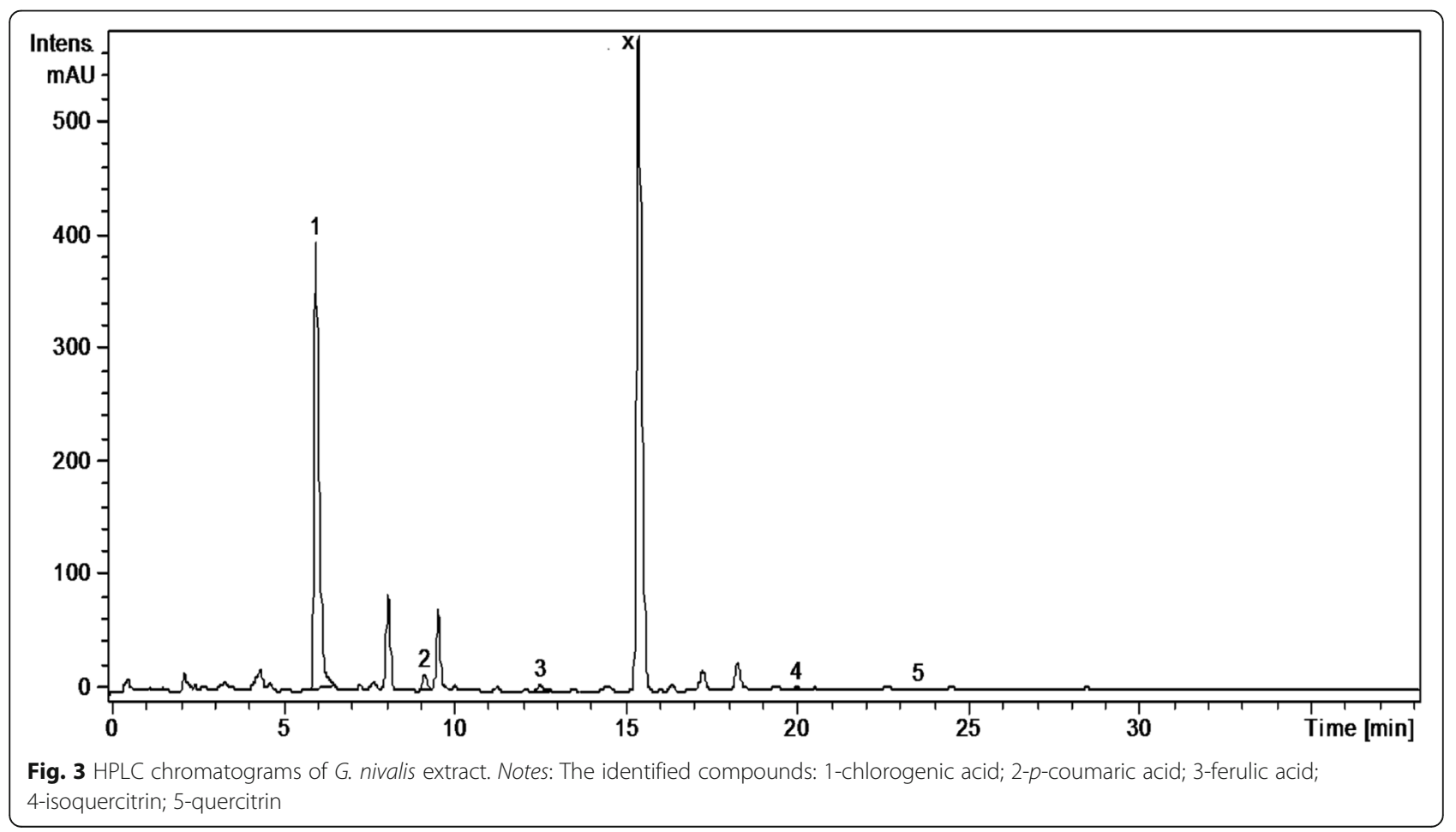




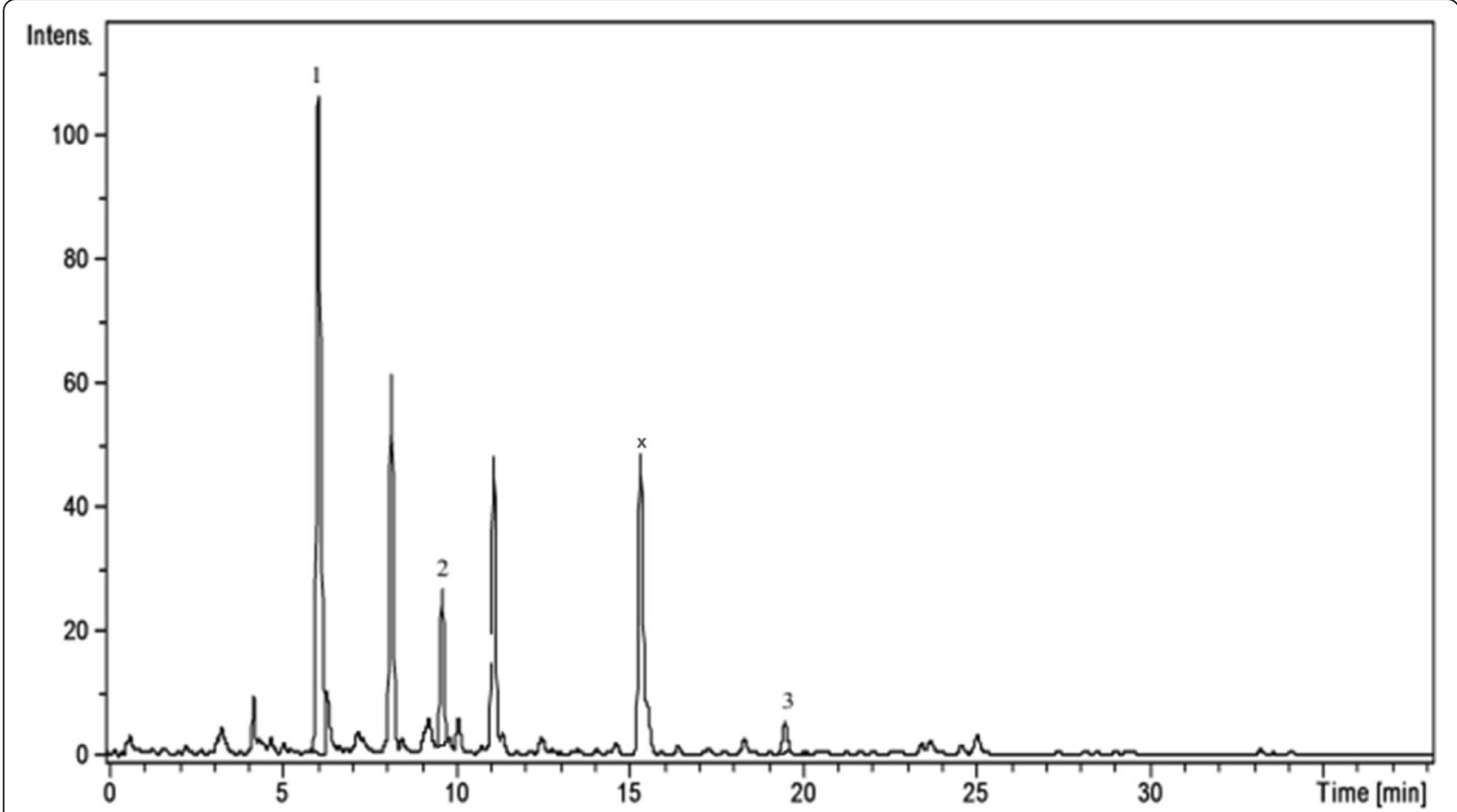

Fig. 4 HPLC chromatograms of L. vernum extract. Notes: The identified compounds: 1-chlorogenic acid; 2-p-coumaric; 3-isoquercitrin

acid was reported as the major constituent, followed by vanillic and ferulic acids [11]. In terms of flavonoids, there are qualitative and quantitative differences between the species examined in the present study. In the N. pseudonarcissus extract, 4 glycosides (hyperoside, isoquercitrin, rutin and quercitrin) and 2 aglycones of flavonoids (quercetin and kaempferol) were determined. Hyperoside was quantified in a large amount $(146.05 \mu \mathrm{g} / \mathrm{g})$, followed by quercitrin $(31.69 \mu \mathrm{g} / \mathrm{g})$. Isoquercitrin, rutin and quercetin were found in too low concentrations to be quantified $(<0.02)$. Isoquercitrin was quantified in $N$. poeticus $(6.59 \mu \mathrm{g} / \mathrm{g}), \quad$ G. nivalis $(25.08 \mu \mathrm{g} / \mathrm{g})$ and $L$. vernum $(8.76 \mu \mathrm{g} / \mathrm{g})$. Quercitrin was determined in $N$. pseudonarcissus $(31.69 \mu \mathrm{g} / \mathrm{g}), N$. poeticus $(9.26 \mu \mathrm{g} / \mathrm{g})$ and $G$. nivalis $(11.13 \mu \mathrm{g} / \mathrm{g})$. Others have identified flavonoids (quercetin, kaempferol etc.) and chlorogenic acid in perianths and coronas of Chinese Narcissus cultivars [13]. Elsewhere, quercetin-3-O-sophoroside and kaempferol-3$O$-sophoroside were found in the tinctures of various Galanthus sp., [4]. In the present study, the HPLC chromatogram of the G. nivalis extract showed a major peak at $\mathrm{Rt}=15.4 \mathrm{~min}$., for which no standards were available. In the fragmentation, this compound (with $\mathrm{m} / \mathrm{z}=625$; marked $\mathrm{x}$ ) has a main fragment with $\mathrm{m} / \mathrm{z} 300$, which could be a quercetin moiety and a fragment with $\mathrm{m} / \mathrm{z}=325$, possible two hexoses (glucose, galactose) (Fig. 3). This compound may also be present in other samples, such as $N$. pseudonarcissus extract, $N$. poeticus extract and $L$. vernum extract (Figs. 1, 2 and 4). Comparing with literature data, the peak could correspond to: quercetin-O-sophoroside or

Table 2 Total polyphenolic content $(\mathrm{mg} / \mathrm{g})$ and the results of antioxidant activities

\begin{tabular}{|c|c|c|c|c|c|}
\hline Samples & TPC mg GAE/g & Flavonoids mg RE/g & DPPH IC $50 \mu \mathrm{g}$ Trolox/mL & FRAP $\mu \mathrm{M}$ Trolox /100 mL & $\operatorname{HAPX}(100)$ \\
\hline N. pseudonarcissus & $19.74 \pm 0.25^{\mathrm{a}}$ & $4.92 \pm 0.17^{c}$ & $>200$ & $220 \pm 10^{e}$ & $11 \pm 4$ \\
\hline N. poeticus & $15.25 \pm 0.06^{b}$ & $2.47 \pm 0.12^{c}$ & $>200$ & $274 \pm 5^{e}$ & $N D^{*}$ \\
\hline G. nivalis & $24.57 \pm 1.42$ & $12.56 \pm 1.43$ & $139.88 \pm 5.11^{e}$ & $725 \pm 18^{e}$ & $35 \pm 12$ \\
\hline L. vernum & $16.49 \pm 0.50^{b}$ & $7.10 \pm 0.09^{d}$ & $>200$ & $238 \pm 7^{e}$ & $N D^{*}$ \\
\hline Trolox & - & - & $11.20 \pm 0.20$ & $2073.91 \pm 26.08$ & - \\
\hline
\end{tabular}

Notes: Each value is the mean \pm SD of three independent measurements

GAE gallic acid equivalent, $R E$ rutin equivalent, Npn Narcissus pseudonarcissus, Np N. poeticus, Gn Galanthus nivalis, Lv Leucojum vernum

${ }^{a} p<0.05$ (Gn versus Npn)

${ }^{\mathrm{b}} p<0.001$ (Gn versus Np, Gn versus Lv)

$c_{p}<0.001$ (Gn versus Npn, Gn versus Np)

$\mathrm{d}_{p}<0.05$ (Gn versus Lv)

$\mathrm{e}_{p}<0.001$ (all samples versus Trolox); ${ }^{*} \mathrm{ND}-$ has not statistically significant effect 


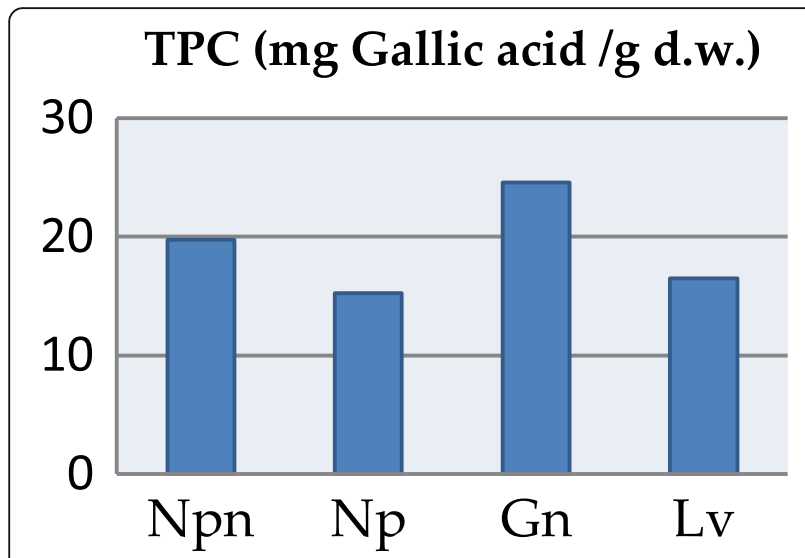

Fig. 5 Total phenol content (TPC) of Amaryllidaceae species

quercetin-3-O-galactosyl-( $1 \rightarrow 6)$-galactoside (molecular weight $=626)$ [4]. The high level of this flavonoidic compound can explain the large amount of total flavonoids in G. nivalis. The HPLC chromatogram of the $N$. poeticus extract showed two peaks at $\mathrm{Rt}=3.30$ and $7.10 \mathrm{~min}$. For which no standards were available. The compounds marked with $y$ and $\mathrm{z}\left([\mathrm{M}-\mathrm{H}]^{-}\right.$ions; $\mathrm{m} / \mathrm{z}$ 353) are presumed to be a type of caffeoylquinic acid: 4-caffeoyl-quinic acid and/or 5-caffeoyl-quinic acid, as isomers of chlorogenic acid, in accordance with literature data [34]. In addition, the chlorogenic acid showed a molecular ion peak at $(\mathrm{m} / \mathrm{z} 353)$ and a fragmentation ion that corresponds to the deprotonated quinic acid $(\mathrm{m} / \mathrm{z}$ 191) [35]. The evaluation of negative electrospray MS spectra shows that compound y has $\mathrm{m} / \mathrm{z}$ value = 353 and is single-charged (the isotopic forms are at $1 \mathrm{amu}$ difference), so the molecular mass is 354 . In the fragmentation, the compound y has a main fragment with $\mathrm{m} / \mathrm{z}$ 191, which could be a quinic acid moiety and a fragment with $\mathrm{m} / \mathrm{z}=179$ which could be the caffeic acid. MS spectra showed that compound $\mathrm{z}$ has the

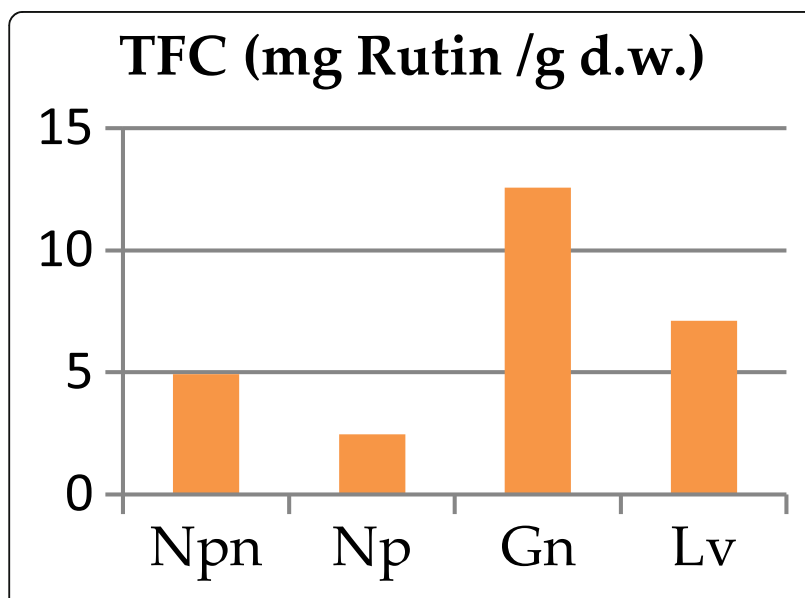

Fig. 6 Total flavonoid content (TFC) of Amaryllidaceae species

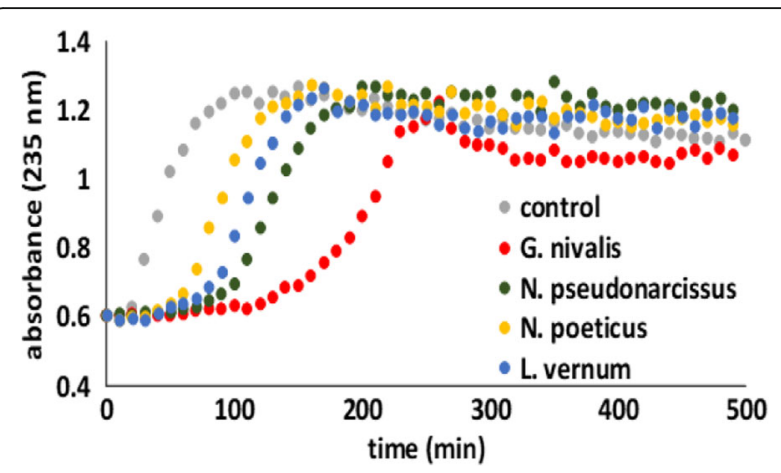

Fig. 7 Liposome oxidation by cytochrome $c$ in the presence of $G$. nivalis, N. pseudonarcissus, N. poeticus and L. vernum extracts, in phosphate buffer, $\mathrm{pH} 7$, at room temperature

molecular weight $=353(\mathrm{M}-\mathrm{H}+)$. In the fragmentation, compound $\mathrm{z}$ has the main fragments with $\mathrm{m} / \mathrm{z}$ values: 173 - resulting from the subsequent loss of water $(-18 \mathrm{Da})$ [quinic acid- $\left.-\mathrm{H}-\mathrm{H}_{2} \mathrm{O}\right]^{-} ; 191$ (quinic acid); 135; 155. We propose a quinic acid ester structure (molecular weight of 354) for compounds y and $z$, based on comparison with literature data: neochlorogenic acid (5-O-caffeoylquinic acid) or/and cryptochlorogenic acid (4-O-caffeoylquinic acid) [34].

Because of their content in chlorogenic acid, the herein examined extracts could be important sources of these active principles (especially G. nivalis), with a great role in preventing various diseases associated with oxidative stress: cancer, cardiovascular, aging, neurodegenerative diseases (Alzheimer's disease) etc. [36, 37]. Also, the $N$. pseudonarcissus extract could be exploited for its hyperoside content, with well-known properties, such as antiviral, antioxidative, antiapoptotic or anti-inflammatory [38].

The total content of polyphenols is considered high if the value is between 12 and $20 \mathrm{mg}$ GAE/g dried plant product [10, 39-41]. In line with this observation, the phenolic content was high for all samples (> $15 \mathrm{mg} \mathrm{GAE} / \mathrm{g}$ ) (Table 2, Fig. 5). In the case of Hungarian L. vernum leaves, a higher total polyphenolic content was noted $(22.71 \mathrm{mg}$ GAE/g) [10]. On the other hand, for the flowers of G. nivalis (from Dobrogea County, Romania) a very low content was reported (0.08-0.13 $\mathrm{mg}$ GAE/g dry weight) [42]. In terms of total flavonoid content, the extract of $G$. nivalis was the richest. A one-way ANOVA test applied on the values flavonoidic content (Table 3 ) showed highly significant differences between $G$. nivalis and both samples of Narcissus $(p<0.001)$ and significant differences between G. nivalis and $L$. vernum $(p<0.05)$.

The antioxidant activity of the extracts measured by DPPH and FRAP was effective in the order G. nivalis > $N$. poeticus $>L$. vernum $>N$. pseudonarcissus. The highest radical scavenging activity was shown by $G$. nivalis $(139.88 \mu \mathrm{g} / \mathrm{mL})$. The other extracts did not show 

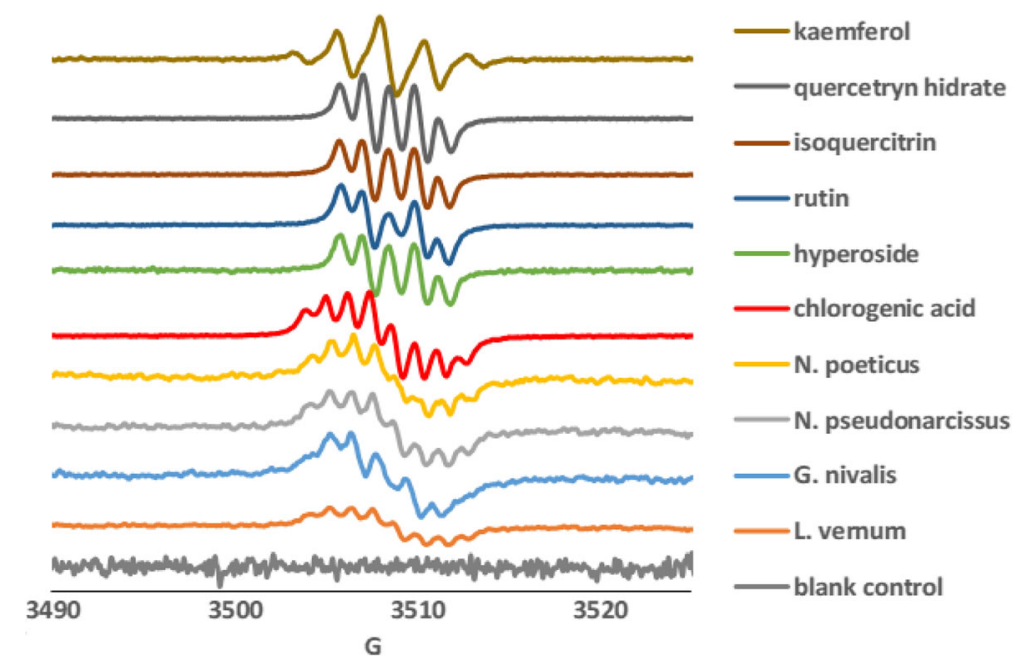

Fig. 8 EPR spectra of Amaryllidaceae species and of references compounds, treated with $\mathrm{NaOH}$, in ethanol $90 \%$. The blank control sample contains only ethanol $90 \%$ and $\mathrm{NaOH}$

antioxidant activity $(>200 \mu \mathrm{g} / \mathrm{mL})$. The antioxidant activity is probably due to the presence of polyphenols, such as flavonoids, caffeic acid derivatives, in the alcoholic extracts [9]. The G. nivalis extract showed 3 times higher antioxidant activity compared to three other extracts $(p<$ $<0.001)$. This activity was statistically significantly inferior to Trolox used as reference antioxidant $(p<<<0.001)$. In good agreement with the trends discussed above, the HAPX effect was measurable only for $G$. nivalis and $N$. pseudonarcissus. For the other samples, no significant results were obtained using 200 -fold diluted extracts; at higher concentrations, the reaction could not be monitored due to the interference between the spectra of hemoglobin and extracts.
The inhibition of lipid peroxidation catalyzed by cytochrome $c$ is based on the interaction of antioxidants with ferryl generated in this case in cytochrome $c$ and/or with free radicals involved in cytochrome-induced autooxidation of lipids [31]. G nivalis exhibits the best antioxidant capacity, reflected in a longer induction time (100 min.) than that observed for $N$. poeticus (40 min.), L. vernum (50 min.) and N. pseudonarcissus (60 min.). Regarding G. nivalis displaying the highest antioxidant capacity of this group, these results are in agreement with DPPH, FRAP and HAPX experiments.

The EPR spectra detected 2 min after alkali treatment of the extracts have a hyperfine structure at room temperature which for N. poeticus and N. pseudonarcissus is very similar

Table 3 Antimicrobial activity of the extracts

\begin{tabular}{|c|c|c|c|c|c|c|}
\hline \multirow[t]{2}{*}{ Samples } & \multicolumn{6}{|c|}{ Diameter of inhibition zone (mm) } \\
\hline & S. enteritidis & E. coli & L. monocytogenes & S. aureus & C. albicans & A. brasiliensis \\
\hline N. pseudo-narcissus & $6 \pm 0.00^{a}$ & $6 \pm 0.00^{a}$ & $12 \pm 1.00^{\mathrm{a}}$ & $14 \pm 1.00^{b}$ & $18 \pm 0.00^{d}$ & $16 \pm 0.00^{f}$ \\
\hline N. poeticus & $6 \pm 0.00^{\mathrm{a}}$ & $6 \pm 0.50^{a}$ & $12 \pm 0.00^{\mathrm{a}}$ & $16 \pm 2.00^{c}$ & $28 \pm 0.50^{e}$ & $22 \pm 0.00^{9}$ \\
\hline G. nivalis & $6 \pm 0.00^{a}$ & $6 \pm 0.00^{\mathrm{a}}$ & $10 \pm 0.50^{\mathrm{a}}$ & $18 \pm 2.00^{c}$ & $6 \pm 0.50^{d}$ & $16 \pm 2.00^{9}$ \\
\hline L. vernum & $6 \pm 0.00^{\mathrm{a}}$ & $6 \pm 0.00^{a}$ & $10 \pm 1.00^{\mathrm{a}}$ & $22 \pm 1.00^{c}$ & $6 \pm 0.00^{d}$ & $6 \pm 0.00^{f}$ \\
\hline Gentamicin & $19 \pm 1.00$ & $18 \pm 1.06$ & $22 \pm 0.50$ & $18 \pm 0.00$ & - & - \\
\hline Fluconazole & - & - & - & - & $25 \pm 1.00$ & - \\
\hline Amphotericin B & - & - & - & - & - & $21 \pm 0.00$ \\
\hline
\end{tabular}

Notes: The values represent the average of three determinations \pm SD. ${ }^{a} p<0.001$ (all sample versus Gentamicin); ${ }^{b} p<0.05$ (Npn versus Gentamicin); ${ }^{c} p>0.05$ ( $\mathrm{Np}, \mathrm{Gn}, \mathrm{Lv}$ versus Gentamicin)

${ }^{\mathrm{b}} p<0.05$ (Npn versus Gentamicin)

$c^{c} p>0.05$ (Np, Gn, Lv versus Gentamicin)

${ }^{d} p<0.001$ (Npn, Gn, Lv versus Fluconazole)

$\mathrm{e}_{p}<0.05$ (Np versus Fluconazole)

${ }^{f} p<0.001$ (Npn, Lv versus Amphotericin B)

${ }^{9} p<0.05(\mathrm{~Np}, \mathrm{Gn}$ versus Amphotericin B)

Gentamicin (10 $\mu \mathrm{g} / \mathrm{disk})$, Fluconazole $(25 \mu \mathrm{g} / \mathrm{disk})$, Amphotericin B $(10 \mu \mathrm{g} / \mathrm{disk})$,) were used as positive controls 
Table 4 Minimum inhibitory concentration (MIC) values

\begin{tabular}{|c|c|c|c|c|c|c|}
\hline \multirow[t]{2}{*}{ Samples } & \multicolumn{6}{|c|}{ MICs $(\mu \mathrm{g} / \mathrm{mL})$} \\
\hline & S. enteritidis & E. coli & L. monocytogenes & S. aureus & C. albicans & A. brasiliensis \\
\hline N. pseudo-narcissus & 625 & 2500 & 156.25 & 78.13 & 39.06 & 78.13 \\
\hline N. poeticus & 625 & 2500 & 78.13 & 78.13 & 19.53 & 19.53 \\
\hline G. nivalis & 625 & 2500 & 312.50 & 19.53 & 1250 & 78.13 \\
\hline L. vernum & 625 & 2500 & 625 & 19.53 & 2500 & 2500 \\
\hline 70\% Ethanol & 625 & 2500 & 1250 & 625 & 2500 & 2500 \\
\hline
\end{tabular}

with that of chlorogenic acid. While the G. nivalis extract contains the highest amount of chlorogenic acid, the EPR signal is not dominated by this species but rather appears to be a mixture of isoquercitrin, quercitrin and chlorogenic acid free radical signals. The spectrum of $L$. vernum is much weaker and has an incompletely defined line shape most probably due to a mixture of isoquercitrin, rutin and quercetrin which are found in a small amount. The free radical signals in all four samples were stable in time and may be attributed to the formation of semiquinone anion radicals within the polyphenols $[29,30]$. According to the HPLC-MS analysis, all extracts contain notable amounts of $p$-coumaric acid; however this compound did not yield EPR signals under the conditions described herein.

With regard to antibacterial activity, all extracts demonstrated anti-staphylococcal activity on S. aureus: G. nivalis extract exhibited antibacterial action similar to gentamicin (inhibition diameter $-18 \mathrm{~mm}$ ) and L. vernum extract demonstrated a higher activity than the reference antibiotic (inhibition diameter $-22 \mathrm{~mm}$ ). This activity could be in accordance with the high content of phenolic acids (chlorogenic acid and $p$-coumaric acid) in the 2 extracts $[43,44]$. The two Narcissus extracts showed moderate anti-staphylococcal activity (inhibition diameter between 14 and $16 \mathrm{~mm})$. All the samples showed less activity on $S$. enterides, E. coli and L. monocytogenes $(p<0.001)$ compared with gentamicin used as reference antibiotic. The activity on $S$. aureus was almost similar with gentamicin for $N$. pseudonarcissus, $N$. poeticus and G. nivalis $(p<0.01)$ and slightly superior for $L$. vernum $(p<0.005)$. The extracts tested on gram-negative bacteria: $S$. enteritidis and $E$. coli have been shown to be inactive (diameter of the inhibition zone $6 \mathrm{~mm}$, as well as the negative control). In terms of antifungal activity, the extract of $N$. pseudonarcissus showed moderate antifungal activity on the two tested fungus (inhibition diameter between 16 and $18 \mathrm{~mm}$ ), whereas $N$. poeticus extract showed a strong effect (C. albicans: inhibition diameter - $28 \mathrm{~mm}$; A. brasiliensis: $22 \mathrm{~mm}$ ), even greater than fluconazole $(p<0.01)$ and amphotericin B $(p=$ 0.02). Some Czech alkaloidal extracts of Narcissus sp. (N. poeticus var. recurvus, $N$. jonquilla) and Leucojum aestivum presented a strong anti-yeast activity [6]. Narcissus $s p$. aqueous extract showed antibacterial action that was explained by the occurrence of polyphenolic compounds in the extract [6]. Regarding the action on $L$. monocytogenes, the activity of the four extracts was weak to moderate (inhibition diameter between 10 and $15 \mathrm{~mm}$ ). In terms of antifungal activity, L. vernum extract was inactive on the two tested fungi (Candida albicans and Aspergillus brasiliensis, diameter $=6 \mathrm{~mm}$ ), while $G$. nivalis extract was inactive on $C$. albicans. Our results suggest that the studied plant extracts showed antibacterial activity against gram positive bacterial strains and antifungal effect. Thus, G. nivalis and L. vernum extracts have demonstrated a good anti-staphylococcal activity, while the $N$. poeticus extract has shown a remarkable anti-Candida effect. Concerning the minimal inhibitory concentration, the lowest MIC values $(19.53 \mu \mathrm{g} / \mathrm{mL})$ were obtained for the G. nivalis and L. vernum extracts against $S$. aureus and also for $N$. poeticus on fungi ( $C$. albicans and $A$. brasiliensis). The results are consistent with those obtained by the diffusion method. Based on these in vitro results, the polyphenolic-rich tested extracts could be used for further studies in order to propose new antimicrobial agents.

\section{Conclusions}

The phenolic profile, antimicrobial and antioxidant activity of some Romanian Amaryllidaceae species (G. nivalis, $N$. pseudonarcissus, $N$. poeticus and $L$. vernum) were analyzed. The results indicated that the aerial parts of these species contain considerable amounts of polyphenols, with chlorogenic acid as major compound. The G. nivalis and $L$. vernum extracts have demonstrated a very good anti-staphylococcal activity, while the $N$. poeticus extract has shown a remarkable anti-Candida albicans effect. These species of Amaryllidaceae family are important not only for the presence of alkaloids, but also for their content in polyphenols in the aerial parts, with a good antimicrobial activity.

The results of our research complete the pharmacognostical characterization of some Amaryllidaceae species with new data and recommend them in further studies on finding alternative sources as anti-staphylococcal and antifungal agents. 


\section{Abbreviations}

d.w.: Dry weight; DPPH: 2,2-diphenyl-1-picrylhydrazyl; FRAP: Ferric reducing antioxidant power; GAE: Gallic acid equivalent; Gn: Galanthus nivalis: HAPX: Hemoglobin ascorbate peroxidase activity inhibition; Lv: Leucojum vernum; MICs: Minimum inhibitory concentrations; Np: N. poeticus; Npn: Narcissus pseudonarcissus; RE: Rutin equivalent; TFC: Total flavonoid content; TPC: Total phenol content; TPTZ: 2,4,6-tri(2-pyridyl)-1,3,5-triazine; Trolox: 6-hydroxy-2,5,7,8-tetramethylchroman-2-carboxylic acid

\section{Acknowledgments}

The authors would like to thank the "Iuliu Hatieganu" University of Medicine and Pharmacy of Cluj-Napoca for financing their project (4944/2/08.03.2016) and to CNCS - UEFISCDI.

\section{Funding}

This work was supported by the "Iuliu Hatieganu" University of Medicine and Pharmacy of Cluj-Napoca by financing the project 4944/2/08.03.2016 (for Dr. $\mathrm{BD}$ ) and also by the Romanian Ministry for Research via CNCS - UEFISCDI (project number PN-II-RU-TE-2014-4-2555).

\section{Availability of data and materials}

All relevant materials and datasets are within this article. Raw data are available from the corresponding author on reasonable request.

\section{Authors' contributions}

$\mathrm{DB}, \mathrm{RSD}, \mathrm{DH}, \mathrm{IO}$, and $\mathrm{LV}$ conceived and designed the experiments; $\mathrm{DB}, \mathrm{CP}$, RSD, DH, IO, MD, BT, AMG, and LV performed the experiments; DB, BT, CP and LV analyzed the data; $D B, C P, M D, R V, A M G$, and LV contributed with reagents/plant materials/analysis tools; $D B, C P, I O$ and $R S D$ have been involved in drafting the manuscript or revising it. All authors have approved the final version.

\section{Ethics approval and consent to participate}

Not applicable.

\section{Consent for publication}

Not applicable.

\section{Competing interests}

The authors declare that they have no competing interests.

\section{Publisher's Note}

Springer Nature remains neutral with regard to jurisdictional claims in published maps and institutional affiliations.

\section{Author details}

'Department of Pharmacognosy, "Iuliu Hațieganu" University of Medicine and Pharmacy, 12 I. Creangă Street, 400010 Cluj-Napoca, Romania. 2Department of Pharmaceutical Technology and Biopharmaceutics, "Iuliu Hațieganu" University of Medicine and Pharmacy, 12 I. Creanga Street, 400010 Cluj-Napoca, Romania. ${ }^{3}$ Department of Chemistry and Chemical Engineering "Babeş-Bolyai" University, 11 A. Janos Street, 400028 Cluj-Napoca, Romania. ${ }^{4}$ State Veterinary Laboratory for Animal Health and Safety, 1 Piata Marasti Street, 400609 Cluj-Napoca, Romania. ${ }^{5}$ Department of Pharmaceutical Chemistry, "Iuliu Hațieganu" University of Medicine and Pharmacy, $41 \mathrm{~V}$. Babeş Street, 400012 Cluj-Napoca, Romania. ${ }^{6}$ University of Agricultural Sciences and Veterinary Medicine, 3-5 Mănăştur Street, 400372 Cluj-Napoca, Romania.

Received: 5 April 2018 Accepted: 18 July 2018

Published online: 27 July 2018

\section{References}

1. Sârbu I, Stefan N, Oprea A. Plante vasculare din România. Determinator ilustrat de teren. Bucharest: (Vascular plants of Romania) Victor B Victor; 2013. p. 991-3.

2. Berkov S, Codina C, Bastid J. The genus Galanthus: a source of bioactive compounds. In: Rao V, editor. Phytochemicals - a global perspective of their role in nutrition and health. InTech; 2012. p. 235-54.
3. Takos AM, Rook F. Towards a molecular understanding of the biosynthesis of Amaryllidaceae alkaloids in support of their expanding medical use. Int J Mol Sci. 2013; https://doi.org/10.3390/ijms140611713.

4. Bokov DO, Samylina IA. Identification of flavonoids in homeopathic mother tinctures of Galanthus woronowii Losinsk. and Galanthus nivalis L. by ultraperformance liquid chromatography with photodiode arrays and tandem quadrupole mass-selective detectors. Pharm Chem J. 2016; https://doi.org/ 10.1007/s11094-016-1469-z.

5. Bokov DO, Malinkin AD, Samylina IA, Vladimirovich BV. Hydroxycinnamic and organic acids of snowdrops (Galanthus L.). J Appl Pharm Sci. 2017; https://doi.org/10.7324/JAPS.2017.70205. https://www.researchgate.net/ publication/315066255_Hydroxycinnamic_and_organic_acids_of_ snowdrops Galanthus_L.

6. Ločárek M, Nováková J, Klouček P, Hošt'álkoviá A, Kokoška L, Gábrlová L, Šafratová M, Opletal L, Cahliková L. Antifungal and antibacterial activity of extracts and alkaloids of selected Amaryllidaceae species. Nat Prod Commun. 2015; https://www.researchgate.net/publication/290439314 Antifungal_and_Antibacterial_Activity_of_Extracts_and_Alkaloids_of_ Selected_Amaryllidaceae_Species.

7. Orhan I, Sener B. Bioactivity-directed fractionation of alkaloids from some Amaryllidaceae plants and their anticholinesterase activity. Chem Nat Compd. 2003; https://www.researchgate.net/publication/227196428_BioactivityDirected_Fractionation_of_Alkaloids_from_Some_Amaryllidaceae_Plants_and_ Their_Anticholinesterase_Activity.

8. Elgorashi EE, Zschocke S, Van Staden J. The anti-inflammatory and antibacterial activities of Amaryllidaceae alkaloids. S Afr J Bot. 2003; https:// doi.org/10.1016/S0254-6299(15)30329-X.

9. Conforti F, Loizzo MR, Marrelli M, Menichini F, Statti GA, Uzunov D, Menichini F. Quantitative determination of Amaryllidaceae alkaloids from Galanthus reginaeolgae subsp. vernalis and in vitro activities relevant for neurodegenerative diseases. Pharm Biol. 2010; https://doi.org/10.3109/13880200903029308.

10. Resetár A, Freytag C, Kalydi F, Gonda S, M-Hamvas M, Ajtay K, Papp L, Máthé C. Production and antioxidant capacity of tissue cultures from four Amaryllidaceae species. Acta Soc Bot Pol. 2017; https://doi.org/10.5586/asbp.3525.

11. Tuzen M, Ozdemir M. Chromatographic determination of phenolic acids in the snowdrop by HPLC. Turk J Chem. 2003; https://www.researchgate.net/ publication/279694582_Chromatographic_determination_of_phenolic_ acids_in_the_snowdrop_by_HPLC.

12. Ivancheva S, Nikolova M, Tsvetkova R. Pharmacological activities and biologically active compounds of Bulgarian medicinal plants. In: Phytochemistry: Advances in researc, Imperato F ed. Kerala: Research Signpost; 2006. p. 87-103.

13. Li X, Lu M, Tang D, Shi Y. Composition of carotenoids and flavonoids in Narcissus cultivars and their relationship with flower color. PLoS One. 2015; https://doi.org/10.1371/journal.pone.0142074. eCollection 2015.

14. Nikolova M, Gevrenova R. Determination of phenolic acids in Amaryllidaceae species by high performance liquid chromatography. Pharm Biol. 2005; https://doi.org/10.1080/13880200590928906

15. Vlase L, Benedec D, Hanganu D, Damian G, Csillag I, Sevastre B, Mot AC, SilaghiDumitrescu R, Tilea I. Evaluation of antioxidant and antimicrobial activities and phenolic profile for Hyssopus officinalis, Ocimum basilicum and Teucrium chamaedrys. Molecules. 2014; https://doi.org/10.3390/molecules19055490.

16. Benedec D, Hanganu D, Oniga I, Tiperciuc B, Olah N, Raita O, Bischin C, Silaghi $R$, Vlase $L$. Assessment of rosmarinic acid content in six Lamiaceae species extracts and their antioxidant and antimicrobial potential. Pak J Pharm Sci. 2015:28(6):2297-303

17. Benedec D, Oniga I, Muresan B, Mot AC, Damian G, Nistor A, Silaghi-DumitresCu R, Hanganu D, Duma M, Vlase L. Contrast between water and ethanol based antioxidant assays: aspen (Populus tremula) and black poplar (Populus nigra) extracts as a case study. J Food Qual. 2014; https://doi.org/10.1111/ffa.12090.

18. Benedec D, Hanganu D, Oniga I, Filip L, Bischin C, Silaghi-Dumitrescu R, Tiperciuc B, Vlase L. Achillea schurii flowers: chemical, antioxidant, and antimicrobial investigations. Molecules. 2016; https://doi.org/10.3390/ molecules 21081050

19. Anton AM, Pintea AM, Rugina DO, Sconta ZM, Hanganu D, Vlase L, Benedec D. Preliminary studies on the chemical characterization and antioxidant capacity of polyphenols from Sambucus sp. Dig J Nanomater Bios. 2013:3:973-80.

20. Prior RL, Wu X, Schaich K. Standardized methods for the determination of antioxidant capacity and phenolics in foods and dietary supplements. J Agric Food Chem. 2005; https://doi.org/10.1021/jf0502698. 
21. Tamokou JDD, Chouna JR, Fischer-Fodor E, Chereches G, Barbos O, Damian G, Benedec D, Duma M, Nkeng Efouet PA, Wabo HK, et al. Anticancer and antimicrobial activities of some antioxidant-rich Cameroonian medicinal plants. PLoS One. 2013; https://doi.org/10.1371/journal.pone.0055880.

22. Singleton VL, Orthofer R, Lamuela-Raventos RM. Analysis of total phenols and other oxidation substrates and antioxidants by means of Folin-Ciocalteu reagent. Methods Enzymol. 1999;299:152-78.

23. Council of Europe, editor. European Pharmacopoeia. 5th ed. Council of Europe. Strasbourg: Cedex; 2005. p. 221.

24. Romanian Pharmacopoeia Commission National Medicines Agency. Romanian Pharmacopoeia. Xth ed. Bucharest: Medical Publishing House; 1993. p. 335.

25. Nastasa C, Tiperciuc B, Duma M, Benedec D, Oniga O. New hydrazones bearing thiazole scaffold: synthesis, characterization, antimicrobial, and antioxidant investigation. Molecules. 2015; https://doi.org/10.3390/ molecules200917325.

26. Liu H, Qiu N, Ding H, Yao R. Polyphenols contents and antioxidant capacity of 68 Chinese herbals suitable for medical or food uses. Food Res Int. 2008; https://doi.org/10.1016/j.foodres.2007.12.012.

27. Pisoschi AM, Negulescu GP. Methods for total antioxidant activity determination: a review. Biochem Anal Biochem. 2011; https://doi.org/10. 4172/2161-1009.1000106

28. Cooper CE, Silaghi-Dumitrescu R, Rukengwa M, Alayash Al, Buehler PW. Peroxidase activity of hemoglobin towards ascorbate and urate: a synergistic protective strategy against toxicity of hemoglobin-based oxygen carriers (HBOC). Biochim Biophys Acta. 2008; https://doi.org/10.1016/j.bbapap.2008.03.019.

29. Mot AC, Damian G, Sarbu C, Silaghi-Dumitrescu R. Redox reactivity in propolis: direct detection of free radicals in basic medium and interaction with hemoglobin. Redox Rep. 2009; https://doi.org/10.1179/ $135100009 \times 12525712409814$.

30. Mot AC, Bischin C, Damian G, Silaghi-Dumitrescu R. Antioxidant activity evaluation involving hemoglobin-related free radical reactivity. Methods Mol Biol. 2015; https://doi.org/10.1007/978-1-4939-1441-8_18.

31. Mot AC, Bischin C, Muresan B, Parvu M, Damian G, Vlase L, Silaghi DR. Antioxidant activity evaluation by physiologically relevant assays based on hemoglobin peroxidase activity and cytochrome $c$-induced oxidation of liposomes. Nat Prod Res. 2015; https:/doi.org/10.1080/14786419.2015.1054824.

32. Benedec D, Hanganu D, Filip L, Oniga I, Tiperciuc B, Olah NK, Gheldiu AM, Raita O, Vlase L. Chemical, antioxidant and antibacterial studies of Romanian Heracleum sphondylium. Farmacia (Bucharest, Rom). 2017;65:252-6.

33. Pașca C, Mărghitaș L, Dezmirean D, Bobiș O, Bonta V, Chirilă F, Matei I, Fiț N. Medicinal plants based products tested on pathogens isolated from mastitis milk. Molecules. 2017; https://doi.org/10.3390/molecules22091473.

34. Masike K, Msizi I, Mhlongo MI, Mudau SP, Nobela O, Ncube EN, Tugizimana F, George MS, Madala NE. Highlighting mass spectrometric fragmentation differences and similarities between hydroxycinnamoyl-quinic acids and hydroxycinnamoyl- isocitric acids. Chem Cent J. 2017; https://doi.org/10. 1186/s13065-017-0262-8.

35. Ibrahim RM, El-Halawany AM, Saleh DO, Naggar MB, El-Shabrawy, Bel-Hawary S. HPLC-DAD-MS/MS profiling of phenolics from Securigera securidaca flowers and its anti-hyperglycemic and anti-hyperlipidemic activities. Rev Bras Farmacogn. 2015;25:134-41.

36. Maalik A, Bukhari SM, Zaidi A, Shah KH, Khan FA. Chlorogenic acid: a pharmacologically potent molecule. Acta Pol Pharm. 2016;73:851-4.

37. Oboh G, Agunloye OM, Akinyemi AJ, Ademiluyi AO, Adefegha SA. Comparative study on the inhibitory effect of caffeic and chlorogenic acids on key enzymes linked to Alzheimer's disease and some pro-oxidant induced oxidative stress in rats' brain-in vitro. Neurochem Res. 2013; https://doi.org/10.1007/s1 1064-012-0935-6.

38. Kim SJ, Um JY, Lee JY. Anti-inflammatory activity of hyperoside through the suppression of nuclear factor-kB activation in mouse peritoneal macrophages. Am J Chin Med. 2011; https://doi.org/10.1142/S0192415X11008737.

39. Amensour M, Sendra E, Abrini J, Pérez-Alvarez JA, Fernández-López J. Antioxidant activity and total phenolic compounds of myrtle extracts. CyTA--J Food. 2010; https://doi.org/10.1080/19476330903161335.

40. Tawaha K, Alali FQ, Gharaibeh M, Mohammad M, El-Elimat T. Antioxidant activity and total phenolic content of selected Jordanian plant species. Food Chem. 2007;104:1372-8.

41. Alali FQ, Tawaha K, El-Elimat T, Syouf M, El-Fayad M, Abulaila K, Nielsen SJ, Wheaton WD 3rd, Falkinham JO, Oberlies NH. Antioxidant activity and total phenolic content of aqueous and methanolic extracts of Jordanian plants: an ICBG project. Nat Prod Res. 2007; https://doi.org/10.1080/14786410701590285.
42. Stanciu G, Chirila E, Dobrinas S, Negreanu-Pirjo T. Studies regarding the determination of antioxidant properties of new plant extracts for cosmetic purposes. Rev Chim (Bucharest, Rom). 2010;61:41-4.

43. Wang L, Bi C, Cai H, Liu B, Zhong X, Deng X, Wang T, Xiang H, Niu X, Wang $D$. The therapeutic effect of chlorogenic acid against Staphylococcus aureus infection through sortase A inhibition. Front Microbiol. 2015; https://doi.org/ 10.3389/fmicb.2015.01031.

44. Li G, Wang X, Xu Y, Zhang B, Xia X. Antimicrobial effect and mode of action of chlorogenic acid on Staphylococcus aureus. Eur Food Res Tech. 2014; https://link.springer.com/article/10.1007/s00217-013-2140-5.

\section{Ready to submit your research? Choose BMC and benefit from:}

- fast, convenient online submission

- thorough peer review by experienced researchers in your field

- rapid publication on acceptance

- support for research data, including large and complex data types

- gold Open Access which fosters wider collaboration and increased citations

- maximum visibility for your research: over $100 \mathrm{M}$ website views per year

At BMC, research is always in progress.

Learn more biomedcentral.com/submissions 